\title{
Działania kulturołwórcze Biblioteki Uniwersytetu Kazimierza Wielkiego
}

STRESZCZENIE: Rok 2019 jest dla Uniwersytetu Kazimierza Wielkiego szczególnie ważny. Bydgoska Uczelnia świętuje 50. lecie swojego istnienia. Wraz z nią jubileusz obchodzi biblioteka, która od samego początku wspiera bydgoską Uczelnię w jej rozwoju. Oprócz zadań dydaktycznych i naukowych, od lat prowadzi ona ciekawą działalność kulturotwórczą. W chwili obecnej dysponuje pięknym, nowoczesnym budynkiem, w którym znajduje się spora przestrzeń wystawiennicza, w tym profesjonalna galeria, a także sale konferencyjne, czytelnie i pracownie. W artykule opisano, jakie działania popularyzujące sztukę, kulturę i wiedzę prowadzili i prowadzą nadal bibliotekarze uczelnianej książnicy od chwili jej powstania po dzień dzisiejszy.

SŁowA KLUCzowe: Biblioteka Uniwersytetu Kazimierza Wielkiego, kultura, biblioteka akademicka.

W ciągu 50. lat istnienia bydgoska uczelnia z Wyższej Szkoły Nauczycielskiej awansowała do rangi uniwersytetu, zaś niewielka, dysponująca w chwili powołania do życia zaledwie 50-tysięcznym księgozbiorem biblioteka, przeistoczyła się w imponującą książnicę uniwersytecką. Od początku istnienia biblioteka starała się tworzyć wartościowe zaplecze naukowe bydgoskiej uczelni. Starannie gromadzony księgozbiór, a w późniejszym czasie także kolekcje cyfrowe, sprzyjały budowaniu 
warsztatu pracy i rozwojowi kadry naukowej oraz umożliwiały kształcenie studentów na coraz to nowych wydziałach i kierunkach studiów dynamicznie rozwijającej się bydgoskiej uczelni.

Każda biblioteka uczelniana, w tym także książnica UKW, jest instytucją kultury ${ }^{1}$. I choć głównym zadaniem biblioteki uniwersyteckiej jest wspieranie uczelni w działaniach na rzecz upowszechniania i pomnażania osiągnięć nauki, pełni ona także rolę kulturotwórczą. Działalność popularyzująca kulturę i sztukę przybiera, zwłaszcza ostatnio, wiele form i służy różnorakim celom. Jednym z nich jest zbudowanie atrakcyjnej przestrzeni, w której ogniskuje się życie lokalnej wspólnoty. Pojęcie biblioteki jako „trzeciego miejsca” jest dziś w środowisku bibliotekarskim bardzo popularne. W Polsce spędzanie wolnego czasu w bibliotece nie cieszy się taką popularnością jak w innych krajach europejskich, jednakże działania wielu książnic, w tym i biblioteki UKW, starają się tę sytuację zmienić2

\section{Wystawiennictwo}

Wystawiennictwo jest najstarszą formą działalności kulturotwórczej bydgoskiej książnicy. W chwili powstania, w 1969 r., biblioteka WSN nie posiadała własnego budynku. Pracowała w trudnych warunkach lokalowych, zajmując rozproszone pomieszczenia w głównym gmachu uczelni przy ul. Chodkiewicza 30. Brakowało wszystkiego: książek, powierzchni magazynowych, miejsc w czytelniach i kadry. Mimo to, od początku istnienia książnicy, w holu uczelni organizowane były wystawy książek. Stały się one zalążkiem działalności kulturotwórczej. W pierwszych latach prezentowano głównie wydawnictwa wieloegzemplarzowe. Brak odpowiednio zabezpieczonych gablot, a także ich niefortunne usytuowanie poza pomieszczeniami biblioteki, uniemożliwiały prezentowanie ciekawych kolekcji ${ }^{3}$. W latach 80 -tych, gdy warunki lokalowe nieznacznie się

1 Bibliotekarstwo, pod red. Anny Tokarskiej, Warszawa 2013, s. 25, 90-100.

2 M. Kisilowska, Czy lubicie się Państwo zakładać? O zaufaniu w bibliotece, [w:] Biblioteka jako „trzecie miejsce”. Międzynarodowa konferencja Biblioteki Uniwersytetu Łódzkiego. Materiały konferencyjne, pod red. Marii Wrocławskiej, Justyny Jerzyk-Wojteckiej, Łódź 2011, s. 12-16.

3 Sprawozdanie z działalności Biblioteki Głównej Wyższej Szkoły Pedagogicznej w Bydgoszczy za rok akademicki 1975/76, Bydgoszcz 1976. 
polepszyły, bibliotekarze organizowali 4-6 wystaw książek rocznie. Kilkakrotnie były też prezentowane najcenniejsze egzemplarze z kolekcji starych druków. Brak specjalnych pomieszczeń uniemożliwiał jednak prowadzenie efektywnej działalności kulturotwórczej .

Sytuacja uległa zmianie w 1993 r., gdy biblioteka przeniosła swoją siedzibę do nowego budynku, usytuowanego tuż przy głównym kampusie Uczelni. W obszernym holu, a także w Czytelni Oddziału Informacji Naukowej, można było organizować wystawy malarstwa, rzeźby czy fotografii artystycznej, a także wernisaże, spotkania z artystami, podróżnikami itp. Warunki nie były idealne, ale zdecydowanie lepsze niż poprzednio. Pierwszym znaczącym wydarzeniem kulturalnym było otwarcie wystawy pt. „W kręgu paryskiej «Kultury»”, w kwietniu 1993 r., udostępnionej przez Muzeum Literatury im. Adama Mickiewicza w Warszawie. W murach książnicy zagościli wówczas po raz pierwszy przedstawiciele środowiska naukowego, świata kultury, a także dziennikarze i użytkownicy biblioteki. Ciekawość odwiedzających bibliotekę gości wiązała się nie tylko z tematyką wystawy. Była to także okazja do zobaczenia nowego gmachu biblioteki uczelnianej, która stała się instytucją popularyzującą kulturę i sztukę. Od tamtej chwili, przez kolejnych niespełna dwadzieścia lat (do przeprowadzki w 2013 r.), w bibliotece odbyło się kilkadziesiąt wernisaży, spotkań z malarzami, rzeźbiarzami, podróżnikami, twórcami fotografii artystycznej itp. Ponieważ cieszyły się rosnącym zainteresowaniem, w 2006 r. została nawiązana współpraca między biblioteką UKW a znaną i cenioną w bydgoskim środowisku artystycznym Galerią Autorską Jana Kaji i Jacka Solińskiego. Jej owocem były prezentowane w murach książnicy wystawy znanych bydgoskich, choć nie tylko, twórców m. in. Bronisława Zygfryda Nowickiego, Michała Candera, Renaty Uzarskiej-Bielawskiej, Jana Kaji, Jerzego Puciaty, Jerzego Riegla, Józefa Zegarlińskiego, Justyny Jułgi, Aleksandra Dętkosia, Wojciecha Nadratowskiego, Jacka Solińskiego i wielu innych. Od 2009 r., w związku z rosnącym zainteresowaniem wystawami, spotkaniami z artystami, a także innymi formami popularyzującymi sztukę, został zainicjowany cykl spotkań pod nazwą „W bibliotece o sztuce”. Osobą odpowiedzialną za ten obszar

${ }^{4}$ H. Dubowik, Biblioteka Główna, [w:] Kronika Wyższej Szkoły Pedagogicznej za okres od 1września 1984 do 31 sierpnia 1989, Bydgoszcz 1989, s. 77-78. 
działalności bibliotecznej została, i pełni tę rolę do dzisiaj, wicedyrektor biblioteki - Barbara Maklakiewicz. Od samego początku spotkania „W bibliotece o sztuce" mają swoją własną formułę. Połączone z wernisażem, stwarzają okazję do poznania sylwetki artysty, twórcy prezentowanych prac, jego poglądów na życie i sztukę, warsztatu artystycznego, źródeł inspiracji itp. Na spotkania zapraszani są także znani bydgoscy krytycy czy historycy sztuki (Hanna Strychalska, Anna Kroplewska-Gajewska), właściciele galerii autorskich (np. Jacek Soliński, Jan Kaja, Elżbieta Kantorek) czy profesorowie UKW (Piotr Siemaszko), których prelekcje są świetnym wprowadzeniem w klimat prezentowanej twórczości. Pięknym akcentem jest oprawa muzyczna spotkań.

Oprócz ekspozycji malarstwa, rzeźby i fotografii organizowanych przez Bibliotekę, w mury książnicy trafiają także wystawy z zewnątrz. Do najciekawszych, zorganizowanych jeszcze w gmachu przy ul. Chodkiewicza 30, należały: „Podhorce. Polsko-ukraińskie badania założeń rezydencjonalnych",prezentująca dokumentację polsko-ukraińskiego programu badawczego, który ze strony polskiej reprezentowany był przez Krajowy Ośrodek Badań i Dokumentacji Zabytków, „Miecz rewolucji. Twarze bydgoskiej bezpieki 1945-1990", przygotowana przez pracowników Oddziałowego Biura Edukacji Publicznej w Gdańsku - Delegatura w Bydgoszczy, „Wystawa przedmiotów i rękodzieła indiańskiego” oraz obrazów o tematyce indiańskiej z okazji Dni Kultury Tubylczych Amerykanów, Wystawa fotografii z Międzyuczelnianego Konkursu Fotograficznego „Flash of life 2008”, „Port Bydgoski” - wystawa zorganizowana przez Muzeum Kanału Bydgoskiego, Magia Australii - wystawa zdjęć i eksponatów Klubu Miłośników Australii i Oceanii w Bydgoszczy i in. ${ }^{5}$.

W latach 1993-2013, w gmachu przy ul. Chodkiewicza 30, bibliotekarze z Oddziału Informacji Naukowej, kilka razy w roku, przygotowywali także małe wystawy, prezentujące zbiory biblioteki w związku z wydarzeniami bieżącymi albo rocznicowymi. Stwarzały one okazję do promowania zasobów biblioteki i były świadectwem zaangażowania książnicy w życie społeczne i kulturalne.

Od 2013 r., po kolejnej przeprowadzce, tym razem do pięknego, funkcjonalnego budynku przy ul. Szymanowskiego 3, działalność wy-

${ }^{5}$ M. Zmitrowicz, Wystawy w Bibliotece Głównej Uniwersytetu Kazimierza Wielkiego w Bydgoszczy, „Bibliotekarz” 2008, nr 6, s. 23-26. 
stawiennicza nabrała jeszcze większego rozmachu. Umożliwiła ją profesjonalna galeria sztuki usytuowana na pierwszym piętrze biblioteki, a także spora przestrzeń wystawiennicza przy wejściu do strefy Wolnego Dostępu oraz w obszernym holu obok galerii, a także w pomieszczeniach pracowni „Pamięć Bydgoszczan i Regionu”. Możliwości lokalowe pozwalają na organizację kilku wystaw jednocześnie. Od 2013 r., w przeciągu niespełna sześciu lat działalności, w nowej bibliotece UKW miało miejsce już przeszło 50 spotkań z cyklu „W bibliotece o sztuce”. Otwierały one wystawy prac: Renaty Uzarskiej-Bielawskiej (malarstwo), Zbigniewa i Adama Papke (malarstwo), Kazimierza Drejasa (malarstwo), Macieja Rewakowicza (fotografia), Mieczysława Ziomka (malarstwo), Jerzego Riegla (fotografia), Kazimiery, Janiny i Krystyny Jułgów (malarstwo), Urszuli Sobkowiak (fotografia), Zygmunta Kotlarczyka (grafika), Jana Kaji (malarstwo), Mieczysława Franaszka (fotografia), Sonii Zengel (malarstwo), Jacka Solińskiego (malarstwo), Włodzimierza Iwanka i wielu innych.

W murach nowej książnicy gościło też przeszło 30 wystaw zorganizowanych przez niezwiązane z biblioteką instytucje. Wśród nich znalazły się m. in.: „Muzealia 2013” - wystawa prezentująca nabytki Muzeum Wyczółkowskiego w Bydgoszczy, „Medycyna wileńska w II Rzeczpospolitej” przygotowana przez Główną Bibliotekę Lekarską w Warszawie, „Sztuka a prawo karne" z Uniwersytetu Europejskiego Viadrina we Frankfurcie nad Odrą, „Bydgostiana” towarzysząca sesji naukowej z okazji 670. rocznicy nadania praw miejskich Bydgoszczy, „Ostatni emisariusz Tadeusz Chciuk-Celt 1916-2001", zorganizowana przez warszawskie Muzeum Historii Ruchu Ludowego, ,Jerzy Giedroyc i jego dzieło. Dorobek Biblioteki „Kultury”, przywieziona z Fundacji Kultury Paryskiej, „Dialog o losie i duszy. Stanisław Vincenz (1888-1971)” przygotowana przez Instytut Filologii Polskiej Uniwersytetu Wrocławskiego oraz „Europa w rodzinie. Ziemiaństwo polskie w XX wieku" zainicjowana przez Instytut Pamięci Narodowej i Polskie Towarzystwo Ziemiańskie. Wśród najnowszych znalazły się: wystawa „Polacy ratujący Żydów w czasie II wojny światowej” przygotowana przez IPN, „Bydgoszcz późnośredniowieczna i nowożytna w świetle badań archeologicznych", kolejna wystawa zorganizowana przez Muzeum Okręgowe im. L. Wyczółkowskiego w Bydgoszczy przy współpracy z Wojewódzkim Urzędem Ochrony Zabytków oraz bydgoskimi archeologami z Sekcji Archeologicznej Towarzystwa Miłośników Miasta Bydgoszczy, a także ekspozycja „Udział mieszkańców Bydgoszczy i okolic 
w Powstaniu Wielkopolskim 1918/1919" opracowana przez Towarzystwo Pamięci Powstania Wielkopolskiego 1918/1919. Wspomniane powyżej wydarzenia są okazją do poszerzenia horyzontów na temat zagadnień, których dotyczą ekspozycje. Uroczystym wernisażom towarzyszą spotkania naukowe, sesje, wykłady. Otwarcie wystawy gromadzi w Bibliotece jej twórców, władze uczelni, naukowców, zainteresowanych tematyką ekspozycji, osoby zaangażowane w wydarzenia, o których one opowiadają, a także użytkowników biblioteki i osoby spoza Uniwersytetu, chcące twórczo i ciekawie spędzić swój czas wolny.

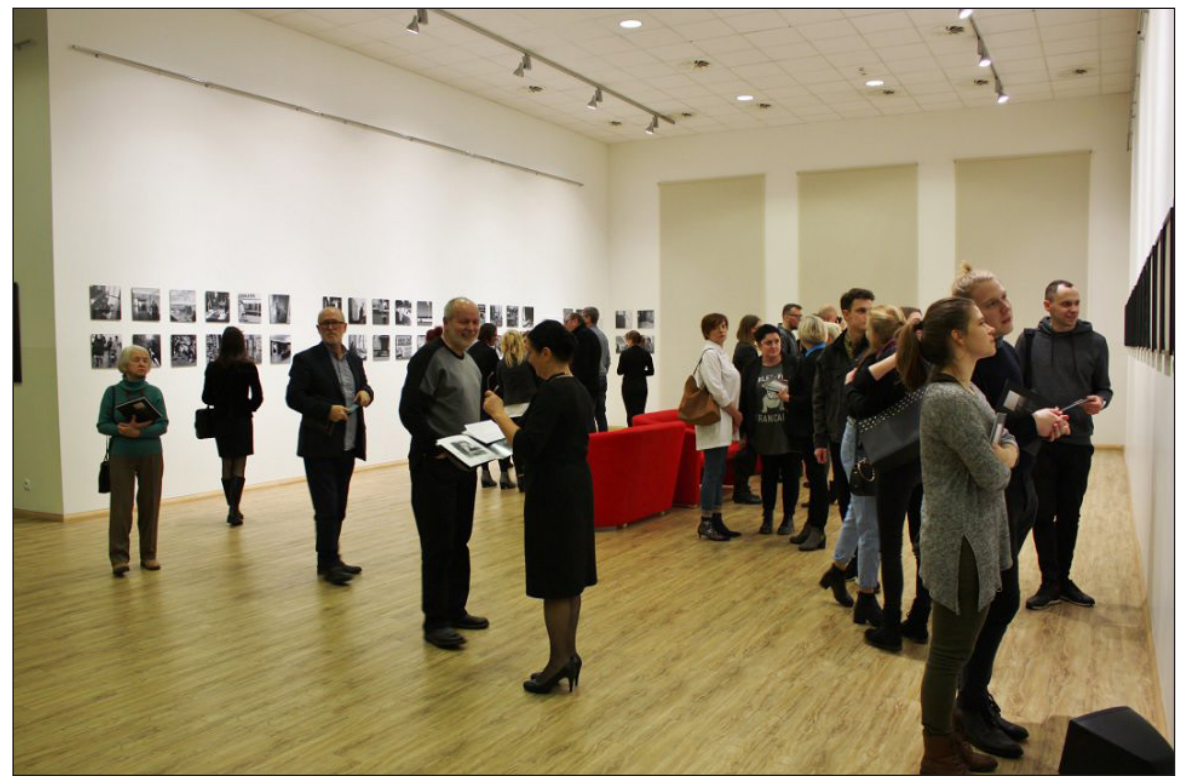

Ilustracja. 1. Otwarcie wystawy fotografii Romualda Fajtanowskiego Źródło: Fot. Katarzyna Mrotek

\section{Spotkania literackie, poetyckie, sesje okolicznościowe, prezentacje i prelekcje}

Głównym zadaniem kulturotwórczym biblioteki jest popularyzacja czytelnictwa. Jedną z jej form - spotkania autorskie z pisarzami lub kluby 
literackie $^{6}$. Wiosną 2012 r. w bibliotece UKW zaczął działalność nieoficjalny klub książki, którego uczestniczki (bibliotekarki i osoby zaprzyjaźnione) spotykały się, żeby porozmawiać na temat ostatnio przeczytanych i wartych polecenia książek ${ }^{7}$. Po przeprowadzce do nowego budynku, w pracowni Pamięć Bydgoszczan i Regionu, w latach 2015-2017 odbywały się Wrota Wyobraźni - akademickie spotkania z literaturą. Ich ideą przewodnią było przybliżenie sylwetek znanych pisarzy i ich książek współczesnemu czytelnikowi. Pomysłodawcą i moderatorem spotkań był Adam Wierzbanowski, producent filmowy. Spotkania z pisarzami, odbywające się w bibliotece naukowej, skierowane były do dorosłych, dojrzałych odbiorców. Dlatego też oprócz pisarza zapraszano również przedstawicieli świata nauki, najczęściej profesorów UKW, literaturoznawców, kulturoznawców, historyków i in., którzy nadawali dyskusji akademicki szlif. Wśród zaproszonych gości znaleźli się: dwukrotnie Jakub Małecki, laureat Nagrody im. Jerzego Żuławskiego (Złote Wyróżnienie), promując: Dygot (styczeń 2016) i Ślady (listopad 2016), Paullina Simons, autorka znanej trylogii Jeździec Miedziany, Tatiana i Aleksander, Ogród letni, z powieścią Samotna gwiazda (maj 2016), Sylwia Chutnik z książką Smutek cinkciarza (grudzień 2016), Jakub Ćwiek z premierową powieścią Grimm City. Wilki (kwiecień 2016), Łukasz Orbitowski z Inną duszq (marzec 2016) i wielu innych. Wrota Wyobraźni, podobnie jak spotkania „W bibliotece o sztuce”, mają ciekawą oprawę artystyczną. Często urozmaicają je występy aktorów czytających fragmenty omawianych utworów literackich, m. in. Mieczysława Franaszka i Alicji Mozgi, reprezentujących bydgoską scenę teatralną czy Michała Zdeba i Ewy Piątek z Teatru niebopiekło. Oprawę muzyczną tworzą studenci Wydziału Edukacji Muzycznej UKW lub zaproszeni muzycy.

W nowej bibliotece odbywają się również wykłady i prelekcje popularyzujące literaturę i sztukę, a także promocje książek niezwiązane z cyklem „Wrota Wyobraźni”. Nie sposób wyliczyć wszystkich imprez. Wśród najciekawszych znalazły się: „Analiza dzieła sztuki” - wykład Renaty Uzarskiej-Bielawskiej, malarki i profesor UKW, spotkania poetyckie:

${ }^{6}$ A. Chlewicka, Działalność bibliotek uniwersyteckich w obszarze kultury, [w:] Kultura w praktyce: zagadnienia prawne, red. Alicja Jagielska-Burduk, Wojciech Szafrański, Poznań 2012, s. 161-175.

7 Tamże, s. 172. 
np. z Mariuszem Stoppelem i Grażyną Wojcieszko, spotkanie autorskie z Krzysztofem Halickim, pracownikiem Muzeum Państwowego w Bydgoszczy, promującym książkę Sekrety Bydgoszczy, wykład z pokazem multimedialnym Marka Chełminiaka pt. „Skarby Katedry Gnieźnieńskiej” i in. W murach książnicy odbywają się także sesje okolicznościowe. Jedna z nich, zorganizowana w kwietniu 2014 r., upamiętniała sylwetkę założyciela i pierwszego dyrektora Biblioteki UKW dr. Henryka Dubowika. Towarzyszyły jej wykłady, otwarcie sali pamiątkowej, wystawa wydawnictw Towarzystwa Miłośników Wilna i Ziemi Wileńskiej, a także spotkanie wspomnieniowe.

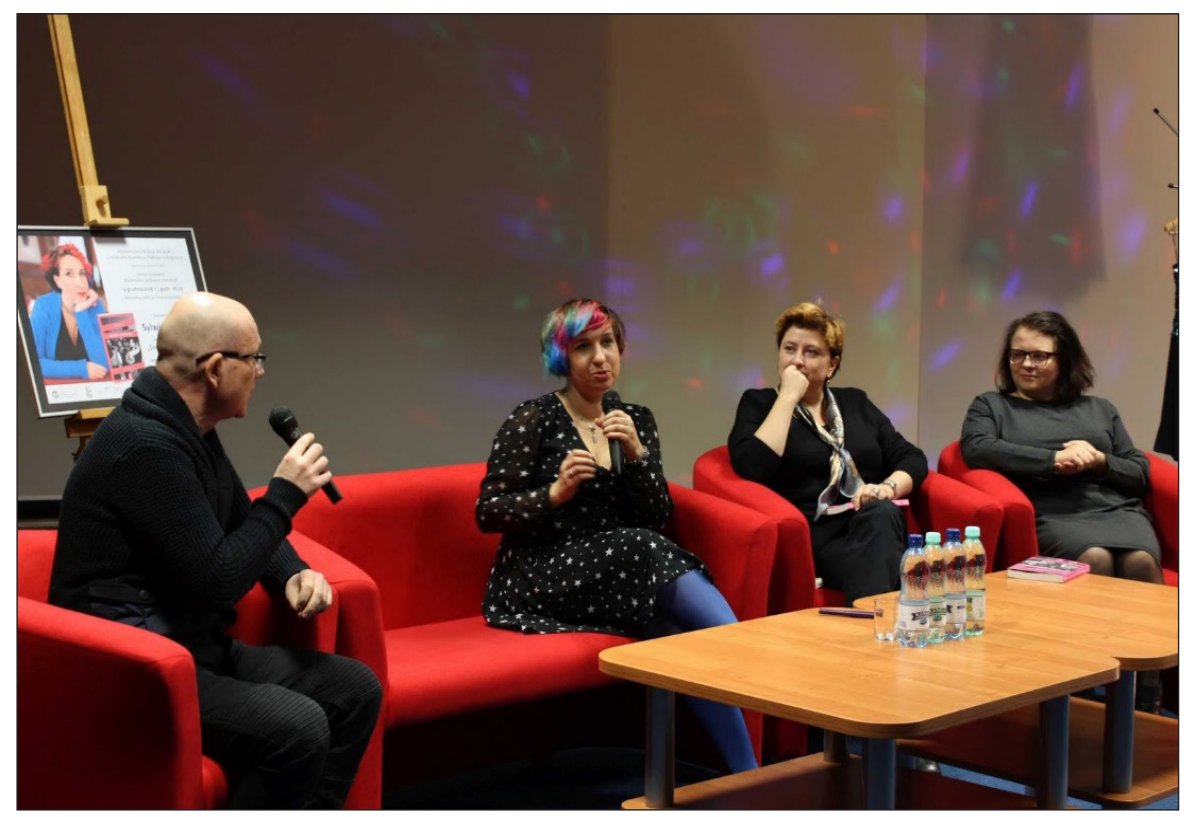

Ilustracja 2. Wrota Wyobraźni z Sylwią Hutnik źródło: Fot. Katarzyna Mrotek

W ramach imprez popularyzujących sztukę w bibliotece odbyły się także: spektakl teatralny pt. „Ja jestem Żyd z Wesela” w wykonaniu aktora bydgoskiej sceny teatralnej Mieczysława Franaszka, wieczór poezji Wisławy Szymborskiej pt. „Nic dwa razy się nie zdarza” w wykonaniu 
studentów edukacji muzycznej pod kierownictwem A. Mozgi, a także pokaz „Przenikanie w tańcu, muzyce i rzeźbie”, podczas którego w bibliotece wystąpił bydgoski Zespół Pieśni i Tańca Płomienie oraz artyści Opery Nova w Bydgoszczy.

\section{Tydzień Bibliotek, Festiwal Nauki, Dzień Bibliotekarza}

Od wielu lat Biblioteka UKW włącza się w organizowaną od 2004 r., z inicjatywy Stowarzyszenia Bibliotekarzy Polskich, akcję pod nazwą Tydzień Bibliotek. Jej celem jest promowanie czytelnictwa i zwrócenie uwagi na biblioteki, jako miejsca przyjazne i otwarte dla każdego. Tydzień Bibliotek rozpoczyna się 8 maja, w Dzień Bibliotekarza. W tym czasie w Bibliotece UKW organizowane są wernisaże, ciekawe wystawy, konkursy, spotkania literackie, wykłady. Pierwsza edycja święta miała miejsce jeszcze w starej bibliotece, w 2010 r. i była ona odpowiedzią na rosnące potrzeby kulturalne społeczności akademickiej ${ }^{8}$. Zorganizowano wówczas prezentację maszyn i urządzeń introligatorskich z kolekcji Leszka Knyrka, odbył się wykład Elżbiety Pokorzyńskiej dotyczący starych opraw, któremu towarzyszyła wystawa. Zaproszono także do biblioteki Jerzego Dudę z Krakowa, Wielkiego Mistrza Rycerskiego Zakonu Bibliofilskiego z kapitułą Orderu Białego Kruka, który opowiedział o motywie książki i biblioteki na znaczkach pocztowych. Zorganizowano trzy spotkania autorskie (z Józefem Banaszakiem, Markiem Jeleniewskim i Zdzisławem Prussem), kiermasz książek Bydgoskiego Domu Wydawniczego Margrafsen oraz wydawnictwa uczelnianego. Do organizacji Tygodnia włączyli się pracownicy biblioteki, a także pracownicy i studenci Katedry Informacji Naukowej i Bibliologii ${ }^{9}$. W nowym budynku, oprócz spotkań autorskich, wystaw, wykładów i prezentacji związanych z książką, czytelnictwem czy literaturą, stałym punktem programu jest zwiedzanie biblioteki. Można także zapoznać się z wybraną kolekcją zbiorów specjalnych, odwiedzić pracownię Pamięć Bydgoszczan i Regionu, wziąć udział w grze terenowej itp.

8 Tamże, s. 165-166.

9 M. Zmitrowicz, „Biblioteka zawsze po drodze...”: Tydzień Bibliotek w książnicy Uniwersytetu Kazimierza Wielkiego w Bydgoszczy, „Bibliotekarz Kujawsko-Pomorski” 2011, nr 2, s. 52-56. 
Ciekawą inicjatywą, skierowaną do pracowników Biblioteki UKW w ostatnich latach, są organizowane z okazji Dnia Bibliotekarza wycieczki do bydgoskich muzeów. Dzięki nim bibliotekarze obejrzeli wystawę zorganizowaną w 125. rocznicę urodzin Teofila Ociepki pt. „Kraj naszej wyobraźni...” oraz podziwiali wystawę „Francisco Goya - między rozumem a szaleństwem", zorganizowaną w Muzeum Okręgowym im. Leona Wyczółkowskiego w Bydgoszczy. Wspólne wyjścia integrują środowisko zawodowe, poszerzają wiedzę i dostarczają wrażeń artystycznych samym bibliotekarzom.

W latach 2003-2009 w bydgoskiej uczelni odbywały się Dni Nauki, które w 2010 r. przekształciły się w Festiwal Nauki. Oprócz UKW, do jego organizacji przyłączyły się inne bydgoskie szkoły wyższe. Wiele z zajęć, warsztatów, wykładów mających na celu popularyzowanie osiągnięć nauki i techniki, a także promowanie kultury i sztuki wśród mieszkańców Bydgoszczy i regionu, odbywa się w bibliotece. Oferta skierowana jest do wszystkich: dzieci, młodzieży, dorosłych i seniorów.

\section{Dni Przyjaźni Polsko-Węgierskiej, Festiwal Kultury Węgierskiej, Wieczory Węgierskie}

W 2012 r., z inicjatywy Biblioteki UKW, zorganizowano w Uczelni uroczystości z okazji Dnia Przyjaźni Polsko-Węgierskiej. Rok później w październiku, tuż po przeprowadzce, Biblioteka wraz z nowopowstałym Bydgoskim Towarzystwem Przyjaciół Węgier (dalej: BTPW) uczciła obchody Dnia Niepodległości Węgier. Od tego czasu corocznie Biblioteka wraz z przedstawicielami BTPW organizuje Dni Przyjaźni Polsko-Węgierskiej, a także Festiwal Kultury Węgierskiej. Wydarzenia te stwarzają użytkownikom biblioteki okazję do uczestniczenia w ciekawych spotkaniach, wykładach, prelekcjach i wernisażach dotyczących polsko-węgierskich relacji na przestrzeni dziejów, a także popularyzujących kulturę, literaturę, sztukę, historię, a nawet kuchnię Węgier. Wśród ciekawszych propozycji oferowanych przez Bibliotekę UKW znalazły się m. in.: koncert muzyki węgierskiej w wykonaniu studentów i pracowników Instytutu Edukacji Muzycznej UKW oraz Państwowego Zespołu Szkół Muzycznych im. Artura Rubinsteina w Bydgoszczy (2013), otwarcie wystawy „Spotkania międzykulturowe” przygotowanej przez Zespół „Dialog Kultur” w Ministerstwie 
Europy, Integracji i Spraw Zagranicznych Austrii (2015), otwarcie wystawy „Pomoc mieszkańców Bydgoszczy dla Węgrów w 1956 r.” (2016), projekcja filmu pt. „Rewolucja Węgierska 1956 - historia i pamięć” (2016), warsztaty animacyjne dla dzieci, a także spotkanie z Ambasador Węgier w RP Orsolyą Zsuzanną Kovacs i prezentacja książki Epizody ze wspólnej historii Polski i Wegier w komiksie (2017), debata społeczna, której inspiracją była promocja książki Eryka Bazylczuka pt. Węgry 1965. Wspomnienia (2017), otwarcie wystawy fotograficznej SándoraKardosa pt. „Archiwum Horusa" (2018) i wiele innych.

\section{Noc Muzeów, współpraca z bydgoskimi muzeami, Muzeum Uniwersyteckie}

Biblioteka UKW, podobnie jak inne instytucje kultury w Polsce, w tym książnice uczelni wyższych, od dobrych kilku lat uczestniczy w dorocznych obchodach Europejskiej Nocy Muzeów. Z tej okazji, w murach biblioteki, a także w uniwersyteckim Muzeum Dyplomacji i Uchodźstwa Polskiego, organizowane są różnorodne imprezy popularyzujące sztukę. Wśród ciekawszych propozycji biblioteki UKW znalazły się: nocne zwiedzanie wystawy pt. „Dar Rodziny Poznańskich z Montrealu” w sali Pamięci Bydgoszczan i Regionu (2015), ekspozycja jednego z najcenniejszych eksponatów z kolekcji uniwersyteckiej - obrazu „Kwiaty” Olgi Boznańskiej i wykład profesora UMK Dariusza Markowskiego pt. „Obrazy za mgłą o warsztacie malarskim Olgi Boznańskiej w aspekcie konserwowanego obrazu <<Kwiaty>>" (2017). W 2018 r. w bibliotece można było posłuchać kilku interesujących wykładów: „Leopold Gottlieb - portret Wandy Poznańskiej, między jawą, a snem - historia i konserwacja jednego obrazu” - Mai Rogowskiej (UMK Toruń), „Historia encyklopedii” - wykład dr Aldony Chlewickiej-Mączyńskiej, „Nowy świat filozofów w Wielkiej Encyklopedii Francuskiej" - wykład dr. hab. Macieja Chlewickiego, prof. UKW oraz „Tysiąc nagrań na portalu Pamięć bydgoszczan”- prezentacja i wystawa przygotowana przez mgr Joannę Kosmeję, poświęcona portalowi Archiwum Bydgoszczan - Pamięć Historii Mówionej. Oprócz tego, goście mogli podziwiać wybrane pozycje encyklopedyczne $\mathrm{z}$ bibliotecznej kolekcji zbiorów specjalnych. 
Działalność kulturotwórcza Biblioteki UKW obejmuje także współpracę z bydgoskimi muzeami. W strukturach biblioteki działa powstałe w 1999 r. Muzeum Dyplomacji i Uchodźstwa Polskiego, gromadzące zbiory dotyczące polskiej służby zagranicznej, dziejów Rządu RP na Uchodźstwie oraz pamiątki obrazujące życie Polonii w różnych częściach świata. Od stycznia 2017 r. zostało ono podporządkowane dyrektorowi Biblioteki UKW $^{10}$. W lutym 2014 r. Biblioteka podpisała umowę z Muzeum Okręgowym im. Leona Wyczółkowskiego w Bydgoszczy. Od tego czasu obie instytucje współpracują ze sobą w zakresie działalności edukacyjnej, naukowo-badawczej oraz wystawienniczej. Owocem tej współpracy są ciekawe eskpozycje ze zbiorów Muzeum Miejskiego, prezentowane w gmachu biblioteki. Warto wymienić: „Muzealia 2013” - nabytki Muzeum Okręgowego im. Leona Wyczółkowskiego w Bydgoszczy (2013), „Bydgoszcz późnośredniowieczna i nowożytna w świetle badań archeologicznych" (2018). We wrześniu 2018 r. w bibliotece UKW odbyła się uroczysta akademia z okazji 95-lecia powstania Muzeum Okręgowego im. Leona Wyczółkowskiego w Bydgoszczy. W listopadzie 2018 r. otwarto ciekawą wystawę pt. „Obrazy Bydgoszczy”, prezentującą dorobek malarzy związanych z bydgoskim środowiskiem artystycznym okresu międzywojennego.

Biblioteka UKW aktywnie uczestniczy w działalności Stowarzyszenia Muzeów Uczelnianych, którego celem jest ochrona dziedzictwa akademickiego jako ważnego wyznacznika tożsamości narodowej ${ }^{11}$. Efektem współpracy jest powstanie, w 2017 r., na mocy zarządzenia Rektora nr 26/2016/2017, Muzeum Uniwersytetu Kazimierza Wielkiego. Znalazło się ono w strukturze biblioteki jako Oddział Zbiorów Muzealnych. Zadaniem muzeum jest gromadzenie materiałów i pamiątek dotyczących historii, organizacji, działalności naukowej, dydaktycznej, kulturalnej i sportowej powstałej w 1969 r. bydgoskiej uczelni. Siedziba placówki znajduje się w Bibliotece. Tam też gromadzone i eksponowane będą jej zbiory ${ }^{12}$.

10 A. Chlewicka-Mączyńska, Działalność Biblioteki Uniwersytetu Kazimierza Wielkiego w Bydgoszczy w obszarze kultury w latach 2013-2017, [w:] Kulturotwórcza rola książki i biblioteki, red. Bożena Sowińska, Bydgoszcz 2018, s. 52-72.

11 Statut Stowarzyszenia Muzeów Uczelnianych [online] [dostęp 7 listopada 2018]. Dostępny w World Wide Web: http://muzeauczelniane.pl/statut.

12 A. Chlewicka, Muzeum Uniwersytetu Kazimierza Wielkiego, [w:] Muzea uczelniane: katalog, red. Hubert Kowalski, Magdalena Grassmann, Marek Bukowski, Joanna Ślaga, Marta Piszczatowska, Warszawa 2017, s. 52. 


\section{Kujawsko-Pomorska Biblioteka Cyfrowa, \\ Pamięć Bydgoszczan}

Biblioteki uniwersyteckie odgrywają znaczącą rolę w dążeniu do zachowania i popularyzowania dziedzictwa kulturowego. Ważną formą działalności w tym obszarze jest tworzenie zasobów cyfrowych. Biblioteka UKW wraz z Biblioteką Uniwersytetu Mikołaja Kopernika w Toruniu są inicjatorami powstania Kujawsko-Pomorskiej Biblioteki Cyfrowej. Celem projektu jest wspieranie edukacji, nauki, turystyki i potencjału intelektualnego społeczeństwa ${ }^{13}$. Zasób biblioteki obejmuje 4 kolekcje, z których co najmniej dwie wpisują się w regionalne działania kulturotwórcze. Kolekcja Dziedzictwo kulturowe gromadzi cyfrowe kopie najcenniejszych zabytków piśmiennictwa (starodruki, rękopisy, zbiory ikonograficzne i in.) znajdujących się w zasobach bibliotek Bydgoszczy i Torunia, zaś kolekcja Regionalia udostępnia cyfrowe wersje książek oraz dokumentów ikonograficznych, kartograficznych i muzycznych dotyczących Pomorza, Kujaw i Ziemi Dobrzyńskiej. W zasobie Regionaliów znajdują się także Vilniana przeszło 2 tys. dokumentów na temat Wilna i Ziemi Wileńskiej. Cały zasób KPBC liczy przeszło 192 tys. publikacji ${ }^{14}$.

Ciekawym pomysłem na wykorzystanie nowych technologii w celu ochrony i popularyzacji dziedzictwa kulturowego jest program „Pamięć Bydgoszczan - Archiwum Historii Mówionej”, zainicjowany przez Bibliotekę UKW w 2011 r. Projekt pozwala na rejestrowanie i popularyzowanie opowieści bydgoszczan dotyczących znaczących dla miasta i jego mieszkańców wydarzeń historycznych i kulturalnych, wyglądu dawnej Bydgoszczy, opisu życia codziennego itp. Zawiera on autentyczne zapisy relacji osób chcących podzielić się swoją wiedzą na temat Bydgoszczy i ciekawymi wspomnieniami. Uzupełnieniem bazy są fotografie i dokumenty archiwalne, które także są cennym materiałem dla badaczy historii i kultury regionu ${ }^{15}$.

${ }^{13}$ Kujawsko-Pomorska Biblioteka Cyfrowa, [online] [dostęp 11 listopada 2018]. Dostępny w World Wide Web: http://kpbc.ukw.pl.

14 Tamże.

15 A. Chlewicka, „Pamięć Bydgoszczan - Archiwum Historii Mówionej” realizacja projektu, [w:] Kultura pamięci. Studia i szkice, red. Aldona Chlewicka, Tomasz Kawski, Bydgoszcz 2013, s. 215. 


\section{Pracownia Dziedzictwa Kulturowego Kresów Wschodnich}

Od 2008 r. w bibliotece UKW działa Pracownia Dziedzictwa Kulturowego Kresów Wschodnich. Powstała na bazie kolekcji przekazanej przez dr. Leszka Jana Malinowskiego oraz zbiorów zlikwidowanego archiwum Bydgoskiego Oddziału Miłośników Wilna i Ziemi Wileńskiej w Bydgoszczy. Jej zasób zasiliły także ankiety osobowe z archiwum Światowego Związku Żołnierzy AK, a także dary od osób prywatnych. Pracownia gromadzi różnego typu dokumenty (wycinki prasowe, zdjęcia, listy, wspomnienia m. in. żołnierzy AK), pochodzące z okresu dwudziestolecia międzywojennego i czasów II wojny światowej, dotyczące Północno-Wschodnich Kresów Rzeczpospolitej ${ }^{16}$. Dzięki żmudnej pracy, mającej na celu opracowanie kolekcji, powstaje bogata baza wiedzy na temat historii i kultury Wileńszczyzny i Kresów z lat 1918-1945.

\section{Zakończenie}

Kulturotwórcza działalność Biblioteki UKW rozwija się od wielu lat. $\mathrm{W}$ nowym gmachu, zaopatrzonym w galerię, liczne przestrzenie wystawiennicze, pracownie oraz sale konferencyjne, bydgoska książnica może podejmować wiele różnych form działalności popularyzującej kulturę, sztukę i naukę. Oferta skierowana jest do wszystkich: pracowników uczelni, studentów, a także mieszkańców miasta, do osób młodych, dzieci, a także seniorów. Każdy znajdzie coś dla siebie.

Informacje o odbywających się w Bibliotece UKW wydarzeniach kulturalnych umieszczane są na stronie Biblioteki, ogłaszane w lokalnych w mediach, m.in. w Bydgoskim Informatorze Kulturalnym, w licznych folderach i informatorach, a także na Blogu biblioteki ${ }^{17}$.

Działalność w zakresie popularyzowania nauki, kultury i sztuki sprawia, że rola biblioteki uczelnianej XXI w. wzrasta. Jest ona centrum wiedzy, stanowi zaplecze dydaktyczne i naukowe Uczelni, a oprócz tego

16 A. Chlewicka-Mączyńska, Działalność Biblioteki..., s. 52-72.

17 Zajrzyj do biblioteki, [online] [dostęp 11 grudnia 2019]. Dostępny w World Wide Web: https://zajrzyjdobiblioteki.blogspot.com/. 
podejmuje się realizacji zadań przypisywanych tradycyjnie bibliotekom publicznym: integruje lokalną społeczność poprzez prowadzenie szerokopasmowej, różnorodnej działalności kulturotwórczej. Jest więc placówką aktywną, inspirującym miejscem spotkań, rozwijającym i twórczym, starającym się jak najpełniej zaspokoić potrzeby społeczności, w której funkcjonuje ${ }^{18}$. Biblioteka UKW poprzez swoją działalność kulturotwórczą w pełni wpisuje się w model nowoczesnej instytucji kultury XXI w.

\section{Bibliografia}

Bibliotekarstwo, red. Anna Tokarska, Warszawa 2017.

Chlewicka Aldona, Działalność bibliotek uniwersyteckich w obszarze kultury,

[w:] Kultura w praktyce: zagadnienia prawne, red. Alicja Jagielska-Burduk, Wojciech Szafrański, Poznań 2012, s. 161-176.

Chlewicka Aldona, Muzeum Uniwersytetu Kazimierza Wielkiego, [w:] Muzea uczelniane: katalog, red. Hubert Kowalski, Magdalena Grassmann, Marek Bukowski, Joanna Ślaga, Marta Piszczatowska, Warszawa 2017, s. 52-57. Chlewicka Aldona, „Pamięć Bydgoszczan - Archiwum Historii Mówionej” realizacja projektu, [w:] Kultura pamięci. Studia i szkice, red. Aldona Chlewicka, Tomasz Kawski, Bydgoszcz 2013, s. 215-227.

Dubowik Henryk, Bibliteka Główna, [w:] Kronika Wyższej Szkoły Pedagogicznej za okres od 1 września 1984 do 31 sierpnia 1989, Bydgoszcz 1989, s. 77-78. Kisilowska Małgorzata, Czy lubicie się Państwo zakładać? O zaufaniu w bibliotece, [w:] Biblioteka jako „trzecie miejsce”. Międzynarodowa konferencja Biblioteki Uniwersytetu Łódzkiego. Materiały konferencyjne, Łódź 2011, s. 18-276.

Kujawsko-Pomorska Biblioteka Cyfrowa [online] [dostęp 11 listopada 2018]. Dostępny w World WideWeb:http://kpbc.ukw.pl.

Pamięć Bydgoszczan - Archiwum Historii Mówionej [online] [dostęp 14 listopada 2018]. Dostępny w World Wide Web: http://pamiecbydgoszczan.ukw.edu. $\mathrm{pl} /$.

Sprawozdanie z działalności Biblioteki Głównej Wyższej Szkoły Pedagogicznej w Bydgoszczy za rok akademicki 1975/76, Bydgoszcz 1976.

18 E. B. Zybert, Pomysły na biblioteki publiczne XXI wieku, [w:] Instytucje kultury jako ośrodki życia społecznego, pod red. Anny Mierzeckiej, Elżbiety Barbary Zybert, Warszawa 2017, s. 14-22. 
Statut Stowarzyszenia Muzeów Uczelnianych [online] [dostęp 7 listopada 2018]. Dostępny w World Wide Web: http://muzeauczelniane.pl/statut.

Zmitrowicz Małgorzata, „Biblioteka zawsze po drodze...”: Tydzień Bibliotek w ksiażंnicy Uniwersytetu Kazimierza Wielkiego w Bydgoszczy, „Bibliotekarz Kujawsko-Pomorski" 2011, nr 2, s. 52-56.

Zmitrowicz Małgorzata, Otwórz wrota wyobraźni, „Bibliotekarz” 2017, nr 6, s. 24-28.

Zmitrowicz Małgorzata, W bibliotece o sztuce „Bibliotekarz” 2015, nr 3, s. 21-25. Zmitrowicz Małgorzata, Wystawy w Bibliotece Głównej Uniwersytetu Kazimierza Wielkiego w Bydgoszczy, „Bibliotekarz” 2008, nr 6, s. 23-26.

Zybert Elżbieta Barbara, Pomysły na biblioteki publiczne XXI wieku, [w:] Instytucje kultury jako ośrodki życia społecznego, red. Anna Mierzecka, Elżbieta Barbara Zybert, Warszawa 2017.

\section{Culture-forming activities of the Library of Kazimierz Wielki University}

ABSTRACT: The year 2019 is especially important for Kazimierz Wielki University, because the academy celebrates its 50th anniversary. In addition to didactic and scientific tasks, the library has been conducting interesting culture-forming activities for years. At present, the library is located in a beautiful and modern building, in which there is a large exhibition space, including a professional gallery, as well as conference rooms, reading rooms and studios. The article describes what activities promoting the art, culture and knowledge were organized and are still carried out by the librarians of the university library from its beginning to the present day.

KEYWORDS: Library of Kazimierz Wielki University, culture, academic library. 